\title{
Avaliação de Alunos Indígenas na Universidade Estadual de Maringá: um ensino adequado à diversidade sociocultural
}

\author{
VALÉRIA SOARES DE ASSIS \\ Antropóloga e Professora de Metodologia da Pesquisa \\ Universidade Estadual de Maringá \\ valeria.assis@terra.com.br
}

\begin{abstract}
Resumo
A partir da análise da proposição de uma avaliação da aprendizagem diferenciada para estudantes indígenas na Universidade Estadual de Maringá - UEM, o texto procura levantar as principais implicações que envolvem o ensino superior para os povos indígenas e refletir sobre elas. Essas reflexões dizem respeito à idéia mais geral de fomentar, na universidade, um diálogo intercultural e nos desafios em atender às demandas de inserção e permanência de indígenas no ensino superior.

Palavras-chave: ensino superior indígena, avaliação diferenciada, diálogo intercultural.
\end{abstract}

\section{Resumen}

A partir del análisis de la propuesta de una evaluación de aprendizaje diferenciado para estudiantes indígenas en la Universidad Estatal de Maringá - UEM, el texto intenta plantear los principales aspectos relacionados a la enseñanza universitária para las comunidades indígenas y reflexionar sobre ellas. Estas reflexiones se refieren a la idea más general de fomentar, en la universidad, un diálogo intercultural y en los desafios de solucionar las necesidades de inserción y permanencia de los indígenas en la enseñanza superior.

Palabras-claves: enseñanza superior indígena, evaluación diferenciada, diálogo intercultural.

\footnotetext{
Abstract

The text raises the main implications involved in teaching Indians at the university and reflects about them, starting with the analysis of a proposal for a distinctive evaluation for Indian students at the State University of Maringá. These reflections tackle the more general idea of fostering intercultural dialogue at the university and the more punctual challenges that consist of meeting the demands of insertion and permanence of Indians at the university.

Key words: indian university, distinctive evaluation, intercultural dialogue.
} 


\section{INTRODUÇÃO}

Este texto pretende apresentar reflexões iniciais ${ }^{1}$ a respeito dos desafios que o ensino superior da UEM enfrenta - relacionados à diversidade sociocultural - especificamente aqueles vivenciados por alguns cursos que possuem estudantes indígenas.

Desde a instalação do vestibular indígena no Paraná, a UEM passou a ter alunos indígenas em alguns de seus cursos regulares. Um dos problemas enfrentados, tanto pelos alunos indígenas quanto por seus professores, eclodiu quando da avaliação desses alunos. Nesse momento, evidenciou-se uma das questões importantes que embasam a dificuldade na viabilização da comunicação intercultural: a compreensão da linguagem usada nessa tentativa de comunicação.

Assim, pretende-se aqui explorar os principais elementos que compõem esse problema. Para tanto, primeiro será feita uma apresentação das questões mais recorrentes que perpassam o ensino formal para os povos indígenas, de forma geral, e do ensino superior, em particular; em seguida serão abordados os problemas de ensino enfrentados na UEM para atender à demanda indígena; as dificuldades encontradas, tanto pelos estudantes indígenas quanto por seus professores, para lidar com a comunicação intercultural evidenciada no momento da avaliação da aprendizagem e, por fim, será apresentada uma análise das possíveis alternativas apontadas para superar esses desafios e aprender com eles.

\section{A EDUCAÇÃO FORMAL PARA OS POVOS INDÍGENAS}

A presença de alunos indígenas na UEM decorre de uma política implantada desde 2002 pelo governo estadual para viabilizar o ingresso de indígenas nas universidades estaduais. Dessa forma, implantou-se o vestibular indígena, um processo seletivo específico para os índios (não só

\footnotetext{
1 Alerto que essas são reflexões a partir de observações vivenciadas no ambiente acadêmico da Universidade Estadual de Maringá e de leituras assistemáticas do tema. Entretanto, embora não seja exatamente o resultado de pesquisa, o conjunto dessas reflexões consiste na formalização de uma hipótese que leva em conta também a experiência (de quase uma década) em pesquisas antropológicas com uma etnia indígena no Rio Grande do Sul, somada à prática docente em cursos de graduação da área de humanas e ciências da saúde, articuladas com o contexto atual da UEM, que tem a freqüência de alunos indígenas, e os debates decorrentes. Vale também lembrar que a presença indígena no ensino superior é muito recente e não há, ainda, estudos sistemáticos publicados a respeito.
} 
do Paraná, mas aberto para qualquer indivíduo de etnia indígena), com vagas extraordinárias em todas as universidades.

$\mathrm{O}$ vestibular indígena e as vagas extraordinárias nas universidades públicas para os índios no Paraná fazem parte de um movimento mais amplo, nacional, de tornar viável, para esse público, o ensino superior. Do ponto de vista legal, a Constituição Federal assegura às sociedades indígenas o direito a uma educação escolar especial (que contemple a diversidade sociocultural e o diálogo intercultural e bilíngüe) em todos os níveis, inclusive no ensino superior (Grupioni, 2000). Hoje a escola, de forma geral, é entendida, por especialistas, como uma conquista para as populações indígenas. Entretanto, ainda há um longo caminho a ser percorrido para que essa conquista legal se torne uma conquista de fato (Silva, Azevedo, 1995).

Um dos pontos polêmicos é o de pensar a própria instituição escolar no interior das aldeias. Para algumas etnias, a presença da escola estruturada da mesma forma que aparece na sociedade englobante é uma realidade de muito tempo e a proposta de mudá-la, para uma revalorização de sua especificidade étnica, constitui um avanço. Por outro lado, as comunidades indígenas, que sempre rejeitaram a "escola do branco", hoje a desejam exatamente exótica e diferente das suas formas étnicas de ensino, para que possam ter domínio de um saber que é próprio da sociedade englobante e, ao mesmo tempo, mantê-la distinta do seu saber tradicional.

Este parece ser o caso dos Mbyá-Guarani no Rio Grande do Sul. No ano 2000, em conversa com um jovem Mbyá, a respeito do tema, ele afirmava, categoricamente, que discordava de conformar os conhecimentos tradicionais do seu povo aos métodos de ensino da escola formal, pois isso implicava submeter um conhecimento a outro. E, ainda, segundo ele, para ser um bom Mbyá, com sabedoria, não era preciso ir à escola² .

Alguns desses problemas se estendem ao ensino superior para as populações indígenas. Umas parecem reivindicar um ensino pautado no viés do diálogo intercultural. Para esses casos, há propostas claras de criação de cursos superiores específicos para esse público, cujo objetivo maior tem sido formar professores indígenas que retornarão às suas comunidades para atender as escolas bilíngües de ensino básico e médio (Desafios..., 2004). Outras, no entanto, ambicionam estar no universo do ensino superior tal qual ele se apresenta. Esta última intenção visa a conhecer e apropriar-se de um saber reconhecido e valorizado na nossa sociedade que será convertido em um instrumento a favor de suas

2 Melià (1995) percebeu os mesmos aspectos em aldeias Guarani, no Paraguai. 
comunidades indígenas num momento em que as relações interétnicas são cada vez mais intensas e imprescindíveis.

De qualquer forma, todo movimento atual para viabilizar o acesso e a manutenção de um público indígena no ensino superior situa-se num contexto impreciso da educação superior no Brasil, próximo de uma reforma universitária. No bojo da proposta de reforma universitária está o objetivo de atender às demandas sociais; dentre elas, a de encontrar alternativas mais adequadas para um ensino superior que atenda aos diferentes projetos, anseios e necessidades dos diversos povos indígenas. $\mathrm{E}$ uma das preocupações recorrentes dos especialistas é a do cuidado na elaboração das propostas, pois corre-se o risco de repetir modelos assistencialistas e de reforçar aqueles já existentes.

\section{O ENSINO SUPERIOR INDÍGENA NO PARANÁ}

A legislação estadual paranaense estabeleceu e garantiu recursos para a implantação do vestibular indígena e a manutenção desses estudantes nos cursos universitários. Como eles precisam se afastar de suas atividades econômicas - que freqüentemente são o suporte para si e sua família - e da comunidade onde vivem, recebem uma ajuda de custo para moradia, alimentação e transporte. Dessa forma, o Estado acredita estar fazendo a sua parte. Entretanto, esses valores são insuficientes para garantir a permanência e o êxito dos índios no ensino superior.

Entre as discussões para a reforma universitária, encontra-se a pauta sobre ações afirmativas de inclusão social, na qual se insere o ensino superior para os povos indígenas. Entretanto, a preocupação em promover o acesso a esse público não se restringe apenas à inclusão social, mas também a um reconhecimento de que vivemos em uma sociedade multicultural. Assim, o Estado deve também ser multicultural e fomentar uma mudança na estrutura universitária que contemple esse aspecto. A presença indígena, portanto, seria uma oportunidade para o diálogo entre o saber acadêmico e o étnico.

Ou seja, de um lado a universidade oferecendo uma formação acadêmica ao índio, permitindo que ele use esse conhecimento como instrumento para a sua autonomia e cidadania (como a administração e gerenciamento de aspectos que afetam sua comunidade na relação com a sociedade englobante, sem a necessidade de intermediação de agentes nãoíndios). E, do outro, a presença indígena levando seu conhecimento, possibilitando o fomento da relativização do saber hegemônico, conjugada com o respeito e o reconhecimento da diversidade sociocultural. 
Observa-se que são proposições que encontram forte resistência na prática. O sistema acadêmico está pautado numa idéia de formação homogênea, elitista e monocultural. Os índios que conseguiram entrar na universidade sofrem discriminação e preconceito. Há um olhar agressivo dirigido constantemente a eles dizendo-lhe que ali não é o seu lugar.

O preconceito mais freqüente advém da idéia de que ele é "naturalmente" incapaz de compreender a linguagem acadêmica. Entretanto, se demonstram capacidade, deixam de ser índios. Tanto uma quanto outra são formas tácitas de negar a diferença.

Percebe-se um constrangimento decorrente de um distanciamento entre uma política de inclusão e as condições reais do meio universitário. Há um evidente despreparo dos recursos humanos para lidar, reconhecer e respeitar as diferenças socioculturais, especialmente uma ausência de qualificação para interagir com estudantes indígenas.

\section{AVALIAÇÃO DA APRENDIZAGEM PARA ALUNOS INDÍGENAS: A ECLOSÃO DE UM PROBLEMA}

Os primeiros anos de presença de alunos indígenas na UEM têm sido de constantes desafios para a instituição, mas especialmente para os próprios índios. Serão enfatizadas aqui as dificuldades e as limitações da instituição com o intuito de refletir como esta pode abrir possíveis caminhos para a superação das mesmas.

O vestibular indígena, desde 2002, instituiu 3 vagas anuais em cada universidade estadual. Assim, a cada ano o vestibular oferece 18 vagas. Atualmente, a UEM possui 7 alunos indígenas, distribuídos em 5 diferentes cursos. Observa-se que, se fosse levado em conta o número anual de vagas, a universidade poderia ter hoje 12 alunos indígenas. Entretanto, verifica-se uma ociosidade de $40 \%$ das vagas. Boa parte delas decorrente de desistência. Pode-se ler essa porcentagem de diferentes maneiras. Uma leitura pertinente é a de que, sem dúvida, tal quadro de ociosidade de vagas indica parte das dificuldades enfrentadas por esses estudantes.

Em 2004, um dos cursos da UEM que possui alunos índios encaminhou ao Conselho de Ensino e Pesquisa da universidade uma solicitação de mudança nos critérios de avaliação da aprendizagem de algumas disciplinas, a fim de atender as especificidades e dificuldades de comunicação dos alunos indígenas. $\mathrm{O}$ argumento utilizado foi o de que esses alunos, devido às dificuldades apresentadas para escrever em português, ficam muito limitados para realizar provas escritas. A 
alternativa apresentada era a de aplicação de provas orais. O Conselho acatou a solicitação e publicou uma resolução com essa alternativa.

Emergia assim, através da avaliação da aprendizagem, o desafio, do ponto de vista pedagógico, de atender as metas de permanência do aluno indígena no ensino superior e do diálogo intercultural. Sem dúvida, é preciso viabilizar alternativas. Entretanto, como já dito anteriormente, elas não podem se configurar em outras formas de tutela e assistencialismo, nem em prejuízo na qualidade do ensino.

Ao se propor um tipo de avaliação da aprendizagem diferenciada para alunos indígenas, percebe-se indícios de desconhecimento da proposta de um diálogo intercultural. Efetivamente, de forma geral, os índios estão sendo recebidos nos cursos e tratados de forma indiferenciada (digo do ponto de vista estrito do ensino em sala de aula). De certa forma, isso pode ser visto como algo bom se o interesse desses estudantes é o da apropriação dos conhecimentos acadêmico-ocidentais.

Por outro lado, a proposta de inserção do índio nesse espaço seria também o de promover algumas reflexões que permitam a incorporação da proposta intercultural. Entretanto, parece que essa diretriz, formalizada no MEC e encampada pelo grupo de especialistas paranaenses nas universidades estaduais, é desconhecida pelos cursos que recebem esses indígenas. Percebe-se aí um desafio importante de tornar viável o ensino superior para essas populações por meio de uma revisão de nossas condutas pedagógicas, de nossos conteúdos teóricos numa perspectiva que seja dialógica, intercultural e que não comprometa a qualidade e os objetivos mais gerais desse tipo de ensino.

\section{NA BUSCA DE ALTERNATIVAS}

O problema da avaliação da aprendizagem nas relações interculturais é precedido de problemas nas formas de aprendizagem interculturais, já que a avaliação é um dos componentes desse processo. Sem dúvida, trata-se de trazer à luz uma dificuldade gerada e desenvolvida em etapas anteriores da educação formal. A educação escolar, oferecida a boa parte do público indígena, está longe de estar adequada ao que prescreve e determina a legislação. É bom ter esse contexto maior em conta.

Porém, como se sabe, o problema da educação formal estende-se a um grupo mais geral. Assim, amplio o problema para os demais calouros que ingressam na universidade. Um número significativo desses alunos chega à universidade com sérias dificuldades para compreender o discurso acadêmico mais elementar. Dentre os problemas de formação, é recorrente 
a crítica que se faz especialmente ao ensino médio, que progressivamente vem se limitando a preparar o estudante para passar no vestibular, quando se esperaria uma aprendizagem mais ampla e adequada. Um ensino médio competente deveria naturalmente preparar para o ingresso no ensino superior, mas não é isso que se verifica (Parizotto, 2005).

Infere-se que o calouro indígena e o não-indígena apresentam dificuldades de aprendizagem semelhantes em relação à sua iniciação em um universo onde impera um tipo específico de discurso. Porém, as dificuldades dos indígenas tornam-se mais graves devido à sua especificidade sociocultural.

A presença da diferença na sala de aula reacende problemas convenientemente esquecidos pelo tempo. O cotidiano da sala de aula distancia-se do que aparece nos programas das disciplinas e das diretrizes mais avançadas. Nega-se a voz do aluno, não há espaço para discutir os problemas que ele traz da sua vivência; algo que deveria acontecer sem prejuízo dos objetivos específicos. O que de fato se presencia é a imposição de temas desinteressantes, distanciando a universidade da realidade do aluno.

Um outro aspecto importante na questão da aprendizagem consiste em avaliar em que medida a comunicação está se processando na sala de aula. Até que ponto há aprendizagem se existe dificuldade de entendimento da via que está sendo utilizada? Desconfia-se que o problema detectado e interpretado na comunicação escrita dos alunos indígenas, no momento da avaliação, é maior do que a dificuldade no domínio da língua portuguesa. Pode-se inferir que seja também uma dificuldade de compreensão de um estilo de discurso, o discurso acadêmico, bem distante daquele comumente conhecido, mesmo em língua portuguesa, que faz parte do senso comum.

Observa-se aí que se trata de um desafio anterior, o de repensar as metodologias em sala de aula para que elas se convertam em um caminho mais adequado de acesso a esse novo discurso. Quais são as metodologias utilizadas em sala de aula que permitem que o aluno conheça realmente um novo saber?

Freqüentemente, os alunos produzem textos tendo pouco conhecimento real daquilo que escreveram. Foram habilitados para reproduzir conhecimento. $\mathrm{E}$, em muitas das formas tradicionais de avaliação da aprendizagem, basta isso para terem êxito. Há um domínio da forma, mas não do conteúdo dos discursos 3 .

3 Sagan (1996) identifica esse aspecto como uma das características do "analfabetismo científico". Izquierdo (2003) aponta na mesma perspectiva. 
Os estudos e as avaliações que fundamentam a viabilização do acesso e permanência de indígenas no ensino superior apresentam como uma das alternativas a comunicação intercultural. Mas como viabilizar essa comunicação? Parece claro que seria importante uma reavaliação das metodologias utilizadas em sala de aula, especialmente sobre o discurso. $\mathrm{O}$ mais conveniente deveria ser o de tornar a linguagem dos discursos acadêmicos mais simples. E, como já foi dito, trata-se de uma demanda geral que é reacesa com a presença indígena.

Reconhece-se que a proposição de uso de uma linguagem mais simples encontra grande resistência. Um dos principais argumentos é o de que se corre o risco de comprometer a qualidade científica do discurso. Entretanto, a resistência encobre incapacidades inconfessáveis e posturas elitistas, algumas vezes não-conscientes. Tornar a linguagem acadêmicocientífica mais simples é plenamente viável, e exemplos não faltam4. Retomando especificamente a proposição de avaliação oral como alternativa para mensurar a aprendizagem de alunos indígenas, questionase em que medida as dificuldades no domínio do discurso não se repetirão, uma vez que se fará uso da língua portuguesa.

De qualquer forma, a alternativa apresentada deve ser entendida como uma estratégia provisória, válida especialmente por permitir que o problema seja evidenciado, e a partir dele procurar-se algo melhor. Entretanto, como é recorrente na universidade, senão em vários âmbitos da nossa sociedade, corre-se o risco dessa solução provisória tornar-se permanente. E é exatamente isso o que se percebe ao constatar que essa alternativa provisória aparece em duas propostas de reformulação curricular de dois cursos da UEM, fazendo crer que, dessa forma, contempla-se o acolhimento e o respeito à diversidade sociocultural, conforme determina a legislação maior.

Evidencia-se, também, que a universidade não está e não foi preparada para receber esse público, e junto com isso refletir sobre a proposição da convivência e respeito às diferenças socioculturais. Boa parte da comunidade acadêmica desconhece a presença de estudantes indígenas, e os professores, especialmente, ficam surpresos com a presença deles na sala de aula.

É necessário habilitar principalmente os docentes para receberem esses alunos e para que abordem suas disciplinas, levando em conta a presença desse novo público. Uma importante alternativa apontada por

4 Além dos autores citados na nota anterior, que são cientistas renomados em suas especialidades e que produzem trabalhos numa linguagem mais acessível para um público não especializado, é possível lembrar também de Stephen Jay Gould, Oliver Sacks e Paul Singer, entre outros. 
especialistas seria a criação de oficinas e seminários dirigidos aos docentes, inclusive de outras instituições de ensino superior para compartilhar experiências e formular alternativas (Desafios..., 2004).

Por outro lado, não se pode negar as dificuldades encontradas pelos estudantes indígenas e a necessidade de dominar o discurso acadêmico. Nesse caso, a alternativa deve ser o acompanhamento e atendimento desses estudantes por uma equipe de apoio extra-classe, seja em oficinas de leituras, em monitorias, em grupos de pesquisa ou de extensão. As formas estatais de apoio à permanência indígena no ensino superior não devem ser restritas a aspectos econômicos. É preciso, igualmente, a presença de uma equipe pedagógica de apoio na universidade.

Tais alternativas se constituem em premissas que permitirão ao estudante indígena realizar sua formação superior em condições menos adversas e, assim, dispensar formas alternativas de avaliação da aprendizagem que, sem dúvida, constrange a todos: alunos e professores.

\section{AS EXPECTATIVAS DOS AGENTES NÃO-INDÍGENAS NO ENSINO SUPERIOR EM RELAÇÃO ÀS POPULAÇÕES INDÍGENAS}

Muitas das ações afirmativas de inserção do índio no ensino superior apresentam como argumento que a formação especializada de alguns indivíduos indígenas reverterá em benefícios para suas comunidades de origem. Essa forma de pensar, embora positiva a princípio, não deve ser encarada como uma condição para o acesso desses indivíduos.

De forma alguma deve ser entendida que a formação de um reduzido número de indivíduos indígenas implica que eles irão retornar para submeter seu aprendizado às demandas de sua etnia. Um indivíduo indígena não pode ser entendido como um apêndice de sua comunidade. Um tentáculo do polvo cultural do qual faz parte.

Trata-se de um indivíduo que mergulha em um novo mundo, sujeito (e disposto) a mudanças na forma de pensar e agir. É um risco que ele e sua comunidade correm e uma escolha que o espera: continuar identificado com sua identidade índia e étnica, retornar à sua comunidade de origem e transformar esse conhecimento em um benefício coletivo ou não. Ele pode continuar sendo índio, mas usar seu conhecimento para convertê-lo em poder, e buscar estratégias para tal na sua comunidade. Ou, ainda, abandonar suas origens e procurar alternativas para se manter na sociedade englobante. 
Se a proposta de acesso ao ensino superior possui como um de seus objetivos que pessoas de diferentes etnias indígenas possam apropriar-se do saber ocidental e usá-lo em benefício de sua comunidade de origem, então é preciso, também, uma proposta para mantê-los na universidade, e que as metodologias sejam pensadas para atingir esses objetivos. E ainda assim se tratará de possibilidades. Da forma como os cursos estão estruturados, e do modo como são conduzidos, dificilmente será possível alcançar tais objetivos.

\section{CONCLUSÃO}

A presença da diversidade cultural e étnica no ensino superior, evidenciada com os índios, deve e pode se constituir num momento rico de reavaliação de nossas metodologias de ensino e mesmo de nossos conteúdos curriculares, diante dos novos contextos que desafiam a universidade. $\mathrm{Ou}$ seja, propostas pedagógicas que contemplem o entrelaçamento de perspectivas. E, nesse caso, o principal desafio do convívio com a diferença é o de manter as alteridades; não de tentar suprimi-las ou de torná-las um jogo de oposições, mas sim entendê-las como complementações.

\section{REFERÊNCIAS BIBLIOGRÁFICAS}

GRUPIONI, Luís Donisete B. Educação e povos indígenas: construindo uma política nacional de educação escolar indígena. Revista Brasileira de Estudos Pedagógicos. v. 81, n. 198, maio/ago. 2000.

IZQUIERDO, Ivan. Silêncio, por favor! São Leopoldo: Unisinos. 2003.

MELIÀ, Bartomeu. Educación indígena y escuela. In: Elogio de la

lengua guarani. Asunción: Centro de Estúdios Paraguayos "Antonio Guash", 1995. p.149-153.

DESAFIOS PARA UMA EDUCAÇÃO SUPERIOR PARA OS POVOS INDÍGENAS NO BRASIL: políticas públicas de ação afirmativa e direitos culturais diferenciados. Relatório. Brasília: LACED, 2004.

PARIZOTTO, Tereza. Por fora, bela viola... Jornal da UEM. Maringá, jan. 2005. p. 3. 
SAGAN, Carl. O mundo assombrado pelos demônios. São Paulo: Cia. das Letras. 1996.

SILVA, Márcio F. da; AZEVEDO, Marta M. Pensando as escolas dos povos indígenas no Brasil: o movimento de professores indígenas do Amazonas, Roraima e Acre. In: SILVA, Aracy L. da; GRUPIONI, Luís Donisete B. (org.) A temática indígena na escola. Brasília: MEC/Mari/Unesco, 1995. p.149-166.

Recebido em: junho 2005

Aprovado para publicação em: agosto 2005 
